\title{
LINFOMAS EM PACIENTES COM A FORMA HEPATOESPLENICA DA ESQUISTOSSOMOSE MANSÔNICA
}

\author{
Álvaro Antônio Bandeira FERRAZ ${ }^{1}$, Vladimir Curvêlo Tavares de SÁ ${ }^{2}$ \\ Edmundo Pessoa de Almeida LOPES ${ }^{3}$, José Guido Corrêa de ARAÚJO Jr. ${ }^{1,4}$, \\ Antônio Cavalcanti de Albuquerque MARTINS ${ }^{1}$ e Edmundo Machado FERRAZ ${ }^{2}$
}

RESUMO - Racional - Cada vez mais se estabelece a correlação entre agentes infecciosos e doenças linfoproliferativas, sobretudo vírus e bactérias, através da ativação de linfócitos. Objetivo - Descrever 6 novos casos, de uma série de 254 pacientes $(2,36 \%)$ com esquistossomose mansônica na forma hepatoesplênica. Casuística e métodos - São descritos 6 pacientes, dentre os 254 portadores de esquistossomose mansônica na forma hepatoesplênica, acompanhados nos últimos 13 anos no Serviço de Cirurgia Geral do Hospital das Clínicas da Universidade Federal de Pernambuco, Recife, PE. Resultados - Todos os seis casos ocorreram em mulheres. Os exames histopatológicos evidenciaram dois casos de linfomas de zona marginal esplênica, um de linfoma de grandes células com imunoblastos, um de linfoma difuso de grandes células, um de linfoma maligno de grandes células não clivadas, e um outro caso de doença de Hodgkin. Metade das seis pacientes evoluiu para o óbito entre 4 a 15 meses após o diagnóstico. As outras três persistem em acompanhamento no Serviço de Oncologia da mesma instituição. Conclusão - A incidência de linfoma nos 254 pacientes acompanhados foi de 2,36\%. Pretende-se chamar a atenção para a ocorrência de linfomas nos baços de pacientes com esquistossomose mansônica, na forma hepatoesplênica.

DESCRITORES - Linfoma. Esquistossomose mansoni.

\section{INTRODUÇÃO}

O número de internamentos hospitalares para tratamento da esquistossomose e suas complicações foi reduzido drasticamente, de 3/10 $000 \mathrm{em} 1989$ para $1,5 / 10000 \mathrm{em} 1995^{(11,17,19,20)}$. Apesar de se verificar redução de cerca de $50 \%$ no número de casos de esquistossomose mansônica (EM) no Brasil nas últimas duas décadas, assim como redução da taxa de mortalidade, a EM continua representando sério problema de saúde pública ${ }^{(6,13,26)}$.

Formas graves da EM continuam a colocar em risco a vida dos pacientes. Cerca de 5\%-8\% dos pacientes esquistossomóticos poderão desenvolver a forma hepatoesplênica e quando o fazem, cerca de $87,5 \%$ deles irão apresentar varizes esofagianas ${ }^{(6,12)}$. A incidência de hemorragia digestiva destes acometidos da forma hepatoesplênica varia entre $11 \%-25 \%(9,10,12,18)$.

A associação de neoplasias malignas tanto epiteliais, como principalmente linfoproliferativa, com esquistossomose hepatoesplênica (EHE) é relatada na literatura como condição relativamente rara, na medida em que referências a esta associação limitam-se a poucos relatos de $\operatorname{casos}^{(3,4,5,22,25)}$. Os primeiros foram registrados na Bahia, em 1969, mas desde então seu número é tão pequeno que se questiona a ocorrência dos dois processos patológicos em um só paciente. Questiona-se se seria apenas coincidência ou se realmente haveria relação de causa-efeito ${ }^{(3,4,5,22)}$.

Nos últimos anos, no entanto, vem-se melhor estabelecendo a correlação entre agentes infecciosos e doenças linfoproliferativas, sobretudo vírus e bactérias, através da ativação de linfócitos ${ }^{(2)}$.

${ }^{1}$ Departamento de Cirurgia da Universidade Federal de Pernambuco (UFPE); ${ }^{2}$ Serviço de Cirurgia Geral do Hospital das Clínicas da UFPE (HC-UFPE); ${ }^{3}$ Departamento de Medicina Clínica da UFPE; ${ }^{4}$ Serviço de Transplante de Órgãos do HC-UFPE, Recife, PE.

Endereço para correspondência: Dr. Álvaro. A. Bandeira Ferraz - Av. Beira Rio 240 - apt. 2501 - Madalena - 50750-400 - Recife, PE. E-mail: aabf@truenet.com.br 


\section{PACIENTES E MÉTODOS}

Descrevem-se 6 pacientes, dentre os 254 com EM na forma hepatoesplênica, acompanhados no período de janeiro de 1992 a dezembro de 2004 no ambulatório do Serviço de Cirurgia Geral do Hospital das Clínicas da Universidade Federal de Pernambuco, Recife, PE (HC-UFPE).

O diagnóstico da esquistossomose foi baseado em dados epidemiológicos, caracterizados por banho de rio em área endêmica, assim como antecedente de hemorragia digestiva alta. Houve ainda a confirmação por biopsia hepática da patologia esquistossomótica.

Caso 1 - feminino, 37 anos, história de perda de peso e linfonodomegalias cervicais, há 2 meses, tendo sido diagnosticado linfoma maligno de grandes células não clivadas, por biopsia de linfonodo cervical, já no estágio IV (comprovado por tomografia axial computadorizada de tórax e abdome). Cerca de 11 meses atrás havia sido esplenectomizada em outro Serviço devido à hipertensão portal e hemorragia digestiva secundária à fibrose periportal da esquistossomose. Iniciou-se tratamento quimioterápico com esquema CHOP (ciclofosfamida, vincristina, doxorrubicina e prednisona) porém a doente foi a óbito por sepse após cerca de 2 meses da admissão hospitalar.

Caso 2 - feminino, 58 anos, história de anemia, febre vespertina, perda de peso, esplenomegalia. A ultra-sonografia revelou hepatoesplenomegalia, fibrose periportal e aumento do calibre das veias porta e esplênica, sendo que o baço apresentava nodulações heterogêneas, além de linfonodomegalias de hilo esplênico. Após a esplenectomia, a microscopia revelou linfoma não-Hodgkin difuso de grandes células. Durante o seguimento pós-operatório, passou a apresentar adenomegalias cervicais e vem sendo acompanhada no Serviço de Oncologia do HC-UFPE.

Caso 3 - feminino, 22 anos, história de hematêmese há 1 ano e 6 meses. A investigação diagnóstica revelou hepatoesplenomegalia, hipertensão portal e fibrose periportal. Havia relato de tratamento para linfoma esplênico, há 7 anos, diagnosticado como doença de Hodgkin. Nessa ocasião, a paciente havia sido tratada com quimioterápicos e evoluía assintomática, sem qualquer evidência de linfoma até a hemorragia digestiva. Foi submetida a esplenectomia e o estudo anatomopatológico do fígado e baço revelou fibrose periportal grau II e esplenomegalia esclerocongestiva. Vem sendo acompanhada há 9 anos sem sinais da doença linfoproliferativa.

Caso 4 - feminino, 58 anos, história de equimoses espontâneas, perda de peso, dor e massa abdominal, além de esplenomegalia gigante. O hemograma identificou plaquetopenia. O exame ultrasonográfico evidenciou fibrose periportal grau II e esplenomegalia gigante, sem linfonodomegalia, e a endoscopia mostrou varizes esofágicas. A tomografia confirmou volumosa esplenomegalia com formações nodulares associada à linfonodomegalia no seu hilo. Foi realizada laparotomia para ressecção do baço, o que não foi possível em virtude da linfonodomegalia perihilar e periaorticocaval. O estudo histopatológico comprovou linfoma maligno de grandes células com predomínio de imunoblastos. A paciente foi submetida a quimioterapia, mas foi a óbito por progressão do linfoma após 4 meses.

Caso 5 - feminino, 44 anos, apresentava dor em hipocôndrio esquerdo e perda de peso, sem passado de hemorragia digestiva ou alterações no hemograma. $\mathrm{O}$ ultra-som e a tomografia mostraram esplenomegalia com imagem nodular de 12 × $11 \mathrm{~cm}$, além de fibrose periportal incipiente. Foi submetida a esplenectomia e o exame histopatológico evidenciou linfoma de células B da zona marginal esplênica. Encontrava-se em acompanhamento no Serviço de Oncologia, quando desenvolveu espessamento de alças intestinais no flanco esquerdo após 1 ano, comprovado por tomografia. Iniciou-se quimioterapia, observando-se regressão da massa. Posteriormente desenvolveu obstrução intestinal, secundária a bridas, complicada por perfuração de alça e óbito por peritonite.

Caso 6 - feminino, 67 anos, história de perda de peso e esplenomegalia gigante. A investigação evidenciou pancitopenia, e ao ultra-som observou-se fibrose periportal, além de esplenomegalia gigante. A endoscopia revelou varizes esofágicas e o mielograma foi normal. Decidiu-se indicar laparotomia exploradora em virtude da volumosa esplenomegalia e da experiência prévia do serviço com outros casos de doença linfoproliferativa. $\mathrm{O}$ achado cirúrgico mostrou fígado esquistossomótico e esplenomegalia gigante, além de sinais de hipertensão portal. O exame histopatológico evidenciou tratar-se de linfoma de zona marginal esplênica com comprometimento hepático. A paciente encontra-se em acompanhamento no Serviço de Oncologia do HC-UFPE.

\section{RESULTADOS}

A idade média foi de 47 anos, variando entre 22 e 67 anos, sendo todas do sexo feminino, com exames pré-operatórios, especialmente ultra-sonografia, que evidenciavam hipertensão portal e fibrose periportal esquistossomótica. Todos os casos eram provenientes de zona endêmica para EM e referiam antecedentes de banhos de rio.

Todas apresentaram fibrose de Symmers ao exame histopatológico do fígado e foram afastados aspectos sugestivos de outras patologias hepáticas, inclusive hepatite viral crônica.

Os exames histopatológicos evidenciaram tratar-se de dois casos de linfomas de zona marginal esplênica: um de linfoma de grandes células com imunoblastos, um de linfoma difuso de grandes células, um de linfoma maligno de grandes células não clivadas, e um outro caso de doença de Hodgkin. Metade dos seis evoluiu para o óbito devido à progressão da doença de base ou por complicações da mesma, sendo entre 4 a 15 meses após o diagnóstico, notando-se não existir relação com a cirurgia. Os outros três persistem em acompanhamento no Serviço de Oncologia do HC-UFPE, estando um deles com cerca de 9 anos sem sinais de atividade do linfoma.

\section{DISCUSSÃO}

Apesar de terem sido relatados 6 casos de linfomas de um total de $254(2,36 \%)$ pacientes com EM na forma hepatoesplênica, a real incidência na presente casuística fica comprometida pelo fato de serem encaminhados ao Serviço de Cirurgia Geral apenas os pacientes com indicação cirúrgica ou para a realização de alguns procedimentos diagnósticos.

Os linfomas constituem grupo heterogêneo de neoplasias que surgem a partir da proliferação monoclonal de uma célula de origem linfóide, que pode ser do tipo $\mathrm{T}$ ou $\mathrm{B}^{(15)}$. Embora fenômenos auto- 
imunes e fatores genéticos possam estar envolvidos, em grande parte dos casos a proliferação é induzida por agentes infecciosos, como vírus ou bactérias. A oncogênese parece ser proporcional à intensidade e continuidade do estímulo imunológico, sendo maior nas infecções crônicas e nos pacientes imunocomprometidos, como os transplantados e naqueles com a síndrome da imunodeficiência adquirida (AIDS). De fato, ultimamente, vem-se descrevendo nítida correlação entre processos linfoproliferativos e o próprio vírus da AIDS, o vírus de Epstein-Barr, o vírus da hepatite $\mathrm{C}$ e o Helicobacter pylori ${ }^{(1,7,14,16,24)}$.

A associação da doença com o vírus Epstein-Barr tem sido suspeitada por dados sorológicos e epidemiológicos. Utilizando a metodologia de hibridização molecular, pode-se isolar o vírus Epstein-Barr em 18\%-50\% dos casos de linfomas. A detecção do genoma do vírus Epstein-Barr aliada ao linfoma está associada ao tipo histológico de celularidade mista, à faixa etária mais jovem e ao baixo nível socioeconômico ${ }^{(21)}$.

A EM é uma enfermidade em que a presença do parasita no organismo determina constantes estímulos imunológicos, estando a resposta primariamente condicionada às células da linhagem linfóide, em especial linfócitos $\mathrm{B}$, linfócitos $\mathrm{T}$ e histiócitos ${ }^{(15)}$. Há evidências de que células componentes do linfoma folicular expressam os mesmos receptores da membrana que os linfócitos $\mathrm{B}$ constituintes do folículo linfóide normal ${ }^{(15)}$. Desta forma, poder-se-ia sugerir que as células neoplásicas são, provavelmente, originárias do linfonodo normal, que submetidas a estímulos repetidos de hiperplasia e regeneração, além de possível susceptibilidade genética, sinalizariam para o desenvolvimento da célula neoplásica do folículo ${ }^{(22)}$. Esse tipo de reação poderia ocorrer em qualquer um dos sítios do tecido linfóide, notadamente linfonodos, medula óssea, pele e mucosa entérica. Essa cadeia de eventos pode ser parcialmente exemplificada através de estudos imunoistoquímicos e histopatológicos de pacientes esplenectomizados com EM, que mostram que a polpa branca pode apresentar várias alterações, incluindo hiperplasia e hipertrofia folicular. A proliferação celular é aspecto importante nas fases iniciais da esplenomegalia ${ }^{(8,23)}$. $\mathrm{O}$ acometimento isolado do baço é condição $\operatorname{rara}^{(15)}$.

Na presente série de pacientes esplenectomizados com EM, encontram-se 6 casos de linfoma dentre 254 acompanhados, no período de 13 anos, o que corresponde a 2,36\%. Em 1971, ANDRADE et al. ${ }^{(5)}$ descreveram a ocorrência de 8 casos de linfoma numa série de 863 esplenectomias em pacientes com EM, que corresponde a 0,9\%. Dez anos após, em São Paulo, PAES et al. ${ }^{(22)}$ descreveram outros 6 casos numa série de 714 esplenectomias, o que equivale à ocorrência de $0,8 \%$. Salienta-se que todos estes 14 casos descritos foram de linfoma folicular gigante.

O maior percentual encontrado no presente estudo poderia ser decorrente do fato deste estudo ter sido desenvolvido em um serviço de cirurgia e, deste modo, receber pacientes com indicação cirúrgica ou necessitado de algum procedimento invasivo, selecionando, desta forma, este tipo de paciente.

Cabe salientar que na série de seis casos todos ocorreram em mulheres, como curiosamente também ocorreram nos 14 referidos em dois estudos anteriores ${ }^{(5,22)}$. Encontra-se apenas um caso descrito no sexo masculino de linfoma histiocítico em pacientes com $\mathrm{EM}^{(3)}$. Não se observam, entretanto, justificativas fisiopatológicas que expliquem a maior ocorrência de linfomas em pacientes com EM do sexo feminino.

Enfim, o presente estudo pretende chamar a atenção, especialmente de cirurgiões e patologistas, para a ocorrência de linfomas nos baços de pacientes com EM, na forma hepatoesplênica. Mais estudos, todavia, serão necessários para avaliar o real papel da infecção esquistossomótica no desenvolvimento de processos linfoproliferativos.

Ferraz AAB, Sá VCT, Lopes EPA, Araújo Jr JGC, Martins ACA, Ferraz EM. Lymphoma in patients harboring hepatosplenic mansonic schistosomiasis. Arq Gastroenterol. 2006;43(2):85-8.

ABSTRACT - Background - Correlation between infectious agents and linfoproliferative diseases are more stablished, over all virus and bacteria, through the activation of linfocytes. Aim - To describe six new cases, of a series of 254 patients (2,36\%) with mansonic schistosomiasis, in the hepatosplenic form. Methods - Six patients will be described, amongst the 254 carriers of mansonic schistosomiasis, in the hepatosplenic form, followed in the last 13 years. Results - All the six cases had occurred in women. The histopathologic examinations had evidenced two cases of marginal splenic zone lymphomas, one of great cells with immunoblasts lymphomas, one diffuse lymphomas, a great cells malignant lymphomas, a great not clivads cells, and another case of Hodgkin. Half of the six evolved for the death 4-15 months after the diagnosis. The others three persist in accompaniment in the Oncology Division of the Clinics Hospital. Conclusion - The incidence of lymphomas in the 254 mansonic schistosomiasis patients followed in our clinic was of 2,36\%. At last, this article intends to call the attention, for the occurrence of lymphomas, in the spleen of patients with mansonic schistosomiasis, in the hepatosplenic form.

HEADINGS - Lymphoma. Schistosomiasis mansoni. 


\section{REFERÊNCIAS BIBLIOGRÁFICAS}

1. Aboulafia DM, Pantanowitz L, Dezube BJ. AIDS-related non-Hodgkin lymphoma: still a problem in the era of HAART. AIDS Read. 2004;14:605-17.

2. Ambinder R. Infection and lymphoma. N Engl J Med. 2003;349:1309-11.

3. Andrade DR, Ishioka S, Câmara-Lopes LH. Associação da esquistossomose mansônica hepatoesplênica e linfoma histiocítico. Arq Gastroenterol. 1982;19:77-80.

4. Andrade ZA, Abreu WN. Linfoma folicular gigante do baço em pacientes com esquistosomosse hepatoesplênica. Gaz Med Bahia. 1969;69:51-64.

5. Andrade ZA, Abreu WN. Folicular lymphoma of the spleen in patients with hepatoesplenic schistosomiasis mansoni. Am J Trop Med Hyg. 1971;20:237-43.

6. Andrade ZA. The situation of hepatosplenic schistosomiasis in Brazil today. Mem Inst Oswaldo Cruz. 1998;93(Suppl 1):313-6.

7. Asaka M, Dragosics BA. Helicobacter pylori and gastric malignancies. Helicobacter 2004;9 Suppl 1:35-41.

8. Carvalho EM, Jesus AR. Baço nas doenças parasitárias. In: Petroianu A, editor. O baço. São Paulo; Belieiro Editores; 2003. p.117-26.

9. Coura JR, Queiroz GC, Florencio CG, Argento CA, Coutinho SG, Figueiredo N, Wanke B, Camillo-Coura L. Morbidade da esquistossomose mansoni no Brasil, estudo de 4.652 casos observados no Rio de Janeiro de 1960 a 1976. Mem Inst Oswaldo Cruz. 1982;77:69-88

10. Cury AA. Hipertensão portal esquistossomótica: história natural. In. Abrantes W, editor. Hipertensão portal - Estado atual. Clin Bras Cir Col Bras Cir. 1995;2(1):121-36.

11. El-Garem AA Schistosomiasis. Digestion. 1998;59:589-605.

12. Ferraz AAB, Silveira MJ, Coelho ARB, Câmara-Neto RD, Araújo Jr GC, Ferraz EM. Surgical treatment of schistosomal portal hypertension. Int Surg. 2001;86:1-8.

13. Ferraz AAB, Lopes EPA, Araújo Jr GC, Lima BA, Cantarelli F, Ferraz EM. Varizes de fundo gástrico na hipertensão portal esquistossomótica: resultados cirúrgicos. Rev Col Bras Cir. 2003;30:21-8.

14. Gisbert JP, García-Buey L, Pajares JM, Moreno-Otero R. Prevalence of hepatitis $\mathrm{C}$ virus infection in B-cell non-Hodgkin's lymphoma: systematic review and metaanalysis. Gastroenterology. 2003;125:1723-32.

15. Hennessey BT, Hanrahan EO, Daly PA. Non-Hodgkin lymphoma: an update. Lancet Oncol. 2004;5:341-53.
16. Hjalgrim H, Askling J, Rostgaard K, Hamilton-Dutoit S, Frisch M, Zhang JS, Madsen M, Rosdahl N, Konradsen HB, Storm HH, Melbye M. Characteristics of Hodgkin's lymphoma after infectious mononucleosis. N Engl J Med. 2003;349:1324-32.

17. Katz N. Schistosomiasis control in Brazil. Mem Inst Oswaldo Cruz. 1998;93(Suppl): $\mathrm{I}: 33-5$

18. Kloetzel K, Kloetzel J. A síndrome hepatoesplênica na esquistossomose mansônica. Considerações sobre uma série de 119 casos. Rev Bras Med. 1958;15:178.

19. Kloetzel K, Schulster NH. Repeated mass treatment of schistosomiasis mansoni: experience in hyperdinamic areas of Brazil. I. Parasitological effects and morbidity. Trans R Soc Trop Med Hyg. 1987;81:365-70.

20. Menezes-Neto AG. Esplenectomia e derivação esplenorenal distal realizadas em Sergipe, antes e após o programa especial de controle da esquistossomose (PECE). Rev Soc Bras Med Trop. 1987;20:41-3.

21. Murad AM. Linfomas e o baço. In: Petroianu A, editor. O baço. São Paulo; Belieiro Editores; 2003. p.180-92.

22. Paes RAP, Maringo C. Linfoma folicular gigante e esquistossomose mansônica. Rev Inst Med Trop São Paulo. 1981;23:287-92.

23. Santos SB, Porto AF, Muniz AL, Jesus AR, Carvalho EM. Clinical and immunological consequences of human T cell leukemia virus type-I and Schistosoma mansoni coinfection. Mem Inst Oswaldo Cruz. 2004;99(5 Supl 1):121-6.

24. Shah MH, Porcu P, Mallery SR, Caligiuri MA. AIDS-associated malignancies. Cancer Chemother Biol Response Modif. 2003;21:717-46.

25. Sherif M, El-Mawla NG, El-Bolkainy N, Badawi S, Awwad H. Clinical staging of malignant lymphoma in patients suspected to have hepato-splenic schistosomiasis. J Trop Med Hyg. 1975; 78:67-70.

26. Silveira RK, Silveira M, Kelner S. Prevalência de sexo, raça e grupo etário entre 3086 portadores de esquistossomose hepatoesplênica. In: Kelner S, Silveira M. Varizes do esôfago na esquistossomose mansônica. Recife: Editora da UFPE; 1997. p.41-53.

Recebido em 4/4/2005 Aprovado em 18/8/2005. 